\title{
Design and Implementation of Infrared Temperature Measurement System
}

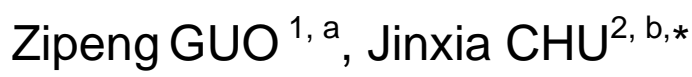 \\ ${ }^{1}$ Automobile Institute, Hubei Polytechnic Institute, Xiaogan 432000, China; \\ ${ }^{2}$ School of Fine Art \& Design, Hubei Engineering University, Xiaogan 432000, China \\ a $409461117 @ q q . c o m,{ }^{b} 346917126 @ q q . c o m$ \\ ${ }^{*}$ Corresponding author
}

Keywords: infrared temperature measurement, hardware design, voice broadcast module.

\begin{abstract}
Infrared temperature measurement system is designed, Based on C51 microcontroller, TN infrared temperature sensor, voice broadcast module and display module design. In this paper, the circuit diagram of hardware design and the flow chart of software algorithm are described. The results show that the infrared temperature meter has the advantages of simple circuit, high reliability, voice broadcast, small size, portability, etc., and can be widely used in families, hospitals, schools, etc., and has good popularization and application prospect.
\end{abstract}

\section{Introduction}

With the rapid development and application of temperature measurement technology, in the face of increasing demand, temperature measurement has wide application prospect in various fields of the temperature measurement technology used in medical work, industrial equipment fault detection, military reconnaissance, civilian daily life etc.[1,4]. The traditional mercury thermometer due to long time measuring and reading trouble and the interference of the body temperature and other shortcomings, has been unable to meet the measurement needs of the people, and the electronic thermometer is due to contact with the patient and bring the risk of infection. Therefore, this paper is the design and the actual demand of fast and effective means of using the non-contact infrared thermometer can be widely used in hospitals, schools and other densely populated areas of temperature detection[5,8].

Based on C51 microcontroller, TN infrared temperature sensor, voice broadcast module and display module design and implementation of infrared temperature measurement system. In this paper, the circuit diagram of hardware design and the flow chart of software algorithm are described.

\section{The Overall Diagram for the Designed System}

The overall diagram for Infrared temperature measurement system is shown in Figure 1, which is composed of MCU, infrared temperature sensor, power supply module, extended keys, the liquid crystal display module and voice broadcast module. the MCU is the microcontroller STC12C5A60S2 using LQFP-44 package with high performance and high performance, the enhanced 8051 core, 36 common IO port, 8 Road the 12 bit ADC module, and other standard peripherals, and can fully meet the system requirements. The infrared temperature sensor directly adopts a commercially available sensor module with digital output, this module is used for collecting and measuring temperature data, and sent the data to the microcontroller port. The extended keys adopts the standard 4 x 4 keyboard, used for human-computer interaction input keys. The liquid crystal display module is the NOKIA 5110 screen to replace the conventional LCD1602, it has a cost-effective, simple interface (only four IO lines can be driven), high-speed (display speed is several times the general LCD12864 or LCD1602), low voltage and low power consumption. this module is used for data display and output of human-computer interaction display. Voice broadcast module is a commercially available voice module, only 3 IO port to achieve voice broadcast control. 


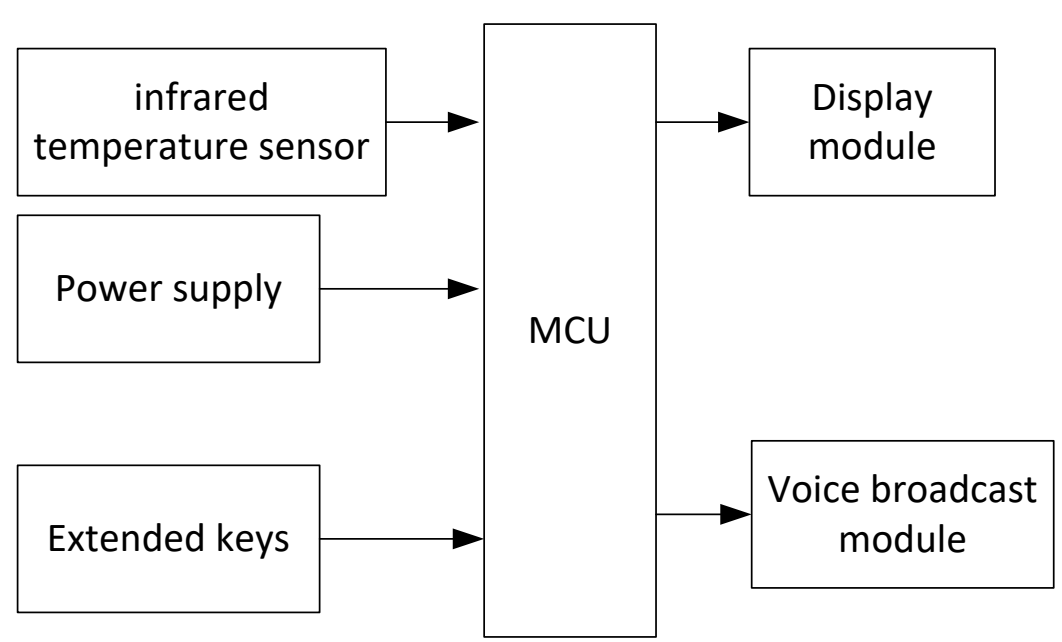

Fig. 1 the overall diagram for the designed system

The infrared sensor continuously collects the human body temperature data, and communicates with the MCU controller. When there is an external key press, the controller reads the sensor temperature data, and carries on the digital smoothing filter, then displays the current temperature data, and carries on the real-time speech broadcast.

\section{The Hardware Design for Designed System}

The Design for MCU Minimum System. The SCM minimum system consists of single-chip controller, clock circuit and reset circuit. The MCU is controller with high performance and high performance price ratio, and the clock circuit is used to provide the reference clock for the minimum system of the MCU.In this design, all of the microcontroller I/O port, the internal timer T0 and serial interrupt is adopted . Specifically as follows:

(1) P0 as LCD LCD screen I/O port.

(2) $\mathrm{P} 1$ as infrared temperature measurement module $\mathrm{I} / \mathrm{O}$ port.

(3) P2 as the data control port of LCD screen.

(4) P3.0 and P3.1 port as voice module serial communication terminal, P3.2 used as voice broadcast control buttons.

The Description for the Infrared Temperature Sensor. The MLX90614 is adopted as the Infrared temperature sensor in this paper, and the sensor is the non-contact infrared thermometer for use with Arduino, or any microcontroller that can communicate with it through its I2C interface. The sensor has the following characteristics: Small size, low cost, 10k Pull up resistors for the I2C interface with optional solder jumpers, Easy to integrate, while the specification is show in table 1. And it can be widely used into Mobile Air-conditioning control system, healthcare and Livestock monitoring.

Table 1 Detailed parameters for GY-906 sensor

\begin{tabular}{cc}
\hline Items & Descriptions \\
\hline Sensor temperature & \multicolumn{1}{c}{$-40 \ldots+125^{\circ} \mathrm{C}$} \\
Measurement accuracy & $0.5^{\circ} \mathrm{C}$ within the range of 0 to $+50{ }^{\circ} \mathrm{C}$ \\
Resolutions & $0.02^{\circ} \mathrm{C}$ \\
Power supply & \multicolumn{1}{c}{$3 \mathrm{~V} \ldots 5 \mathrm{~V}$} \\
& \multicolumn{1}{c}{ single and dual zone versions, } \\
Others & $\begin{array}{l}\text { SMBus compatible digital interface and } \\
\text { customizable PWM output for } \\
\end{array}$ \\
& continuous-reading \\
\hline
\end{tabular}

The Circuit of the Power Supply. Power supply circuit is shown in Figure 2, the input power is $+5 \mathrm{~V}$ VCCIN. When switch K1 is press, the system is connected to the power supply. The input $+5 \mathrm{~V}$ power supply filtered by the capacitor C1 and C2, is sent to two ASM1117, which will be converted 
to $+5 \mathrm{~V}$ power supply $+3.3 \mathrm{~V}$. For security considerations, the use of two pieces of ASM1117 redundant output design. In addition, the Power indicating circuit consisted of the R2 and D4, is set up in this circuit. when the power is turned on, D4 will light.

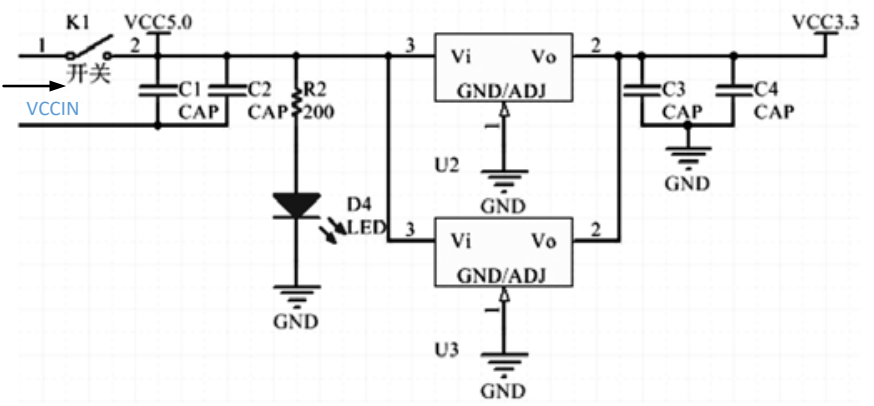

Fig. 2 the Circuit of the power supply

Interface Circuit of Controller and Liquid Crystal Display Module. The controller and the interface circuits of liquid crystal display module as shown in Figure 3, 1th pin and 8th pin of 5110 display is connected to $+3.3 \mathrm{~V}$ power supply, while the 2th pin of 5110 display is ground. For other pins, the 3th pin connect to the microcontroller P2.0 port, 4th pin connect to the microcontroller P2.1 port, 5th pin connect to the microcontroller P2.2 port, 6th pin connect to the microcontroller P2.3 port, 7th pin connect to the microcontroller P2.4 port,. Through the simple 5 connecting lines, you can achieve the connection between the microcontroller and the display screen, greatly reducing the occupation of IO port.

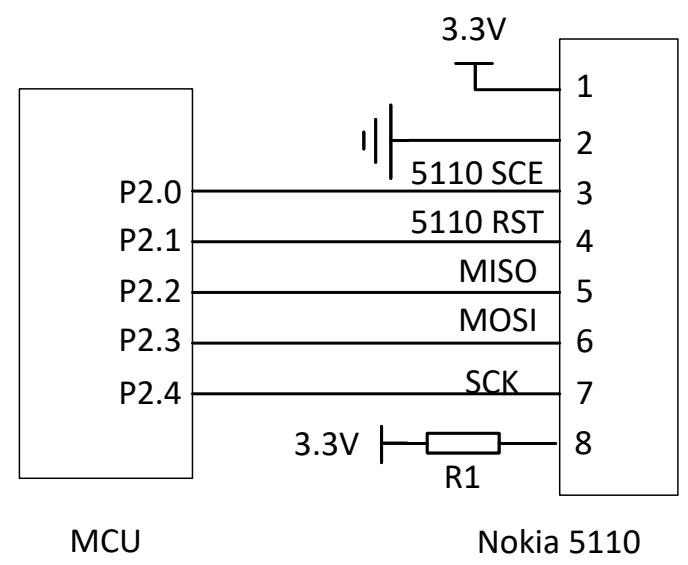

Fig. 3 Interface circuit of controller and liquid crystal display module

\section{The Flow Chart for the Designed Software}

The main program module to complete the system initialization, temperature detection, serial port communication, display and other functions. The system initialization includes the initialization of the timer interrupt, the initialization of the serial communication interrupt, the initialization of the LCD display. Specification are as follows:

(1) Infrared temperature measurement module includes: obtain temperature data, calculate the temperature value, send data to the microcontroller.

(2) Voice module: the use of voice broadcast button, read the microcontroller data, broadcast data through the speaker.

(3) Display module: MCU data acquisition, display temperature data.

when the infrared thermometer is connected to the power supply, the STC89C51 microcontroller starts to run the program. The program first STC89C51 microcontroller initialization, and then wait for the timing interrupt, read the temperature sensing data of the infrared temperature measurement module, after the data smoothing filter, the display module to send data. Finally, to determine whether there is an external interrupt (i.e. whether to press the button for voice broadcast), if there is no 
external interrupt, then continue to determine if there is an external interrupt; otherwise, sends the data to the voice module through the serial communication, the voice module will receive the data through the speaker.

\section{Conclusions}

Compared with the traditional method of temperature measurement, infrared temperature measurement has the advantages of no need to contact the measured object, convenient measurement, high measuring speed and high precision, and is widely used in the temperature measurement of the family, the hospital and other fields. So, based on the C51 microcontroller collocation of a small amount of external sensors, the design and implementation of infrared temperature measurement system is achieved, and tested, related results show that with thermometer design of high precision, good stability, has a good prospect of market

\section{Acknowledgement}

We would like to express our thanks to ours students for their valuable discussions and helps to ready for ours experiment. This work has been supported by the key project of Hubei Provincial Department of Education: D20152703.

\section{References}

[1] Huang R S, Liu L M, Song G. Infrared temperature measurement and interference analysis of magnesium alloys in hybrid laser-TIG welding process[J]. Materials Science and Engineering: A, 2007, 447(1): 239-243.

[2] Maier C. Infrared temperature measurement of polymers[J]. Polymer Engineering \& Science, 1996, 36(11): 1502-1512.

[3] Childs P R N, Greenwood J R, Long C A. Review of temperature measurement[J]. Review of scientific instruments, 2000, 71(8): 2959-2978.

[4] Snyder W C, Wan Z, Zhang Y, et al. Classification-based emissivity for land surface temperature measurement from space[J]. International Journal of Remote Sensing, 1998, 19(14): 2753-2774.

[5] Avenas Y, Dupont L, Khatir Z. Temperature measurement of power semiconductor devices by thermo-sensitive electrical parameters-A review[J]. IEEE Transactions on Power Electronics, 2012, 27(6): 3081-3092.

[6] Ring E F J, Ammer K. Infrared thermal imaging in medicine[J]. Physiological measurement, 2012, 33(3): R33.

[7] Agrawal M, Vasyuchka V I, Serga A A, et al. Direct measurement of magnon temperature: New insight into magnon-phonon coupling in magnetic insulators[J]. Physical review letters, 2013, 111(10): 107204.

[8] Yoo J, Estrada-Perez C E, Hassan Y A. An accurate wall temperature measurement using infrared thermometry with enhanced two-phase flow visualization in a convective boiling system[J]. International Journal of Thermal Sciences, 2015, 90: 248-266. 